\title{
Optimization, purification and characterization of a- glucosidase inhibitors from Streptomyces costaricanus EBL.HB6 isolated in Vietnam
}

\section{Thi Trung Nguyen}

Graduate University of Science and Technology

Thi Hong Thao Phan

Institute of Biotechnology

Phuong Dai Nguyen Nguyen

Tay Nguyen University

Thi Mai Anh Dao

Hanoi University of Pharmacy

Van Hien Mai

Hanoi University of Pharmacy

Tuyen Thi Do ( $\nabla$ dttuyen@ibt.ac.vn )

Institute of Biotechnology, Vietnam Academy of Sience and Technology https://orcid.org/0000-00028048-5794

\section{Research Article}

Keywords: Purification, optimal conditions, Streptomyces costaricanus EBL.HB6, a-glucosidase inhibitors (AGIs)

Posted Date: September 28th, 2021

DOl: https://doi.org/10.21203/rs.3.rs-931347/v1

License: (a) (1) This work is licensed under a Creative Commons Attribution 4.0 International License. Read Full License 


\section{Abstract}

\section{Background}

Diabetes, a disease that has been a great burden of the treatment cost for patients and society. There are many drugs have been used to cure this disease available on the pharmaceutical market. One of the most prevalent source to produce these compounds are microorganism. Among them, Streptomyces sp. are popular microorganisms used for the production of a-glucosidase inhibitors (AGIs).

\section{Methods and Results}

In this study, different cultivation conditions were optimized to enhance the production of AGIs. Purification and evaluation of AGIs from S. costaricanus EBL.HB6 were also performed. Our results demonstrated that Streptomyces costaricanus EBL.HB6 had the highest a-glucosidase inhibitory activity among 6 Streptomyces sp. strains were isolated in Vietnam. The 16S rRNA sequencing of isolating HBC62 indicated $99 \%$ identity to the corresponding sequence of Streptomyces costaricanus, and was registered on GenBank with the code MT 453944.1. Streptomyces costaricanus EBL.HB6 was able to produce melanin yellow pigment, and its aerial and substrate mycelia have brown and yellow-grey pigment on ISP2 cultivating medium, respectively. The a-glucosidase inhibitory activity of the supernatant was increased by a factor of 1.2 under optimal conditions (media containing $1.5 \%$ glucose, $1.2 \%$ yeast extract at $28^{\circ} \mathrm{C}$, initial $\mathrm{pH}$ of 6.5 , and culture time for $120 \mathrm{~h}$ ) in comparison with the initial media and condition. The purified efficacy of a-glucosidase inhibitors was $5 \%$ with a retention factor of 0.71 on thin-layer chromatography and $\mathrm{IC}_{50}$ value of $9.59 \mathrm{mg} / \mathrm{mL}$.

\section{Conclusions}

Streptomyces costaricanus EBL.HB6 strain was selected, purified and evaluated for its highly producible of a-glucosidase inhibitors.

\section{Introduction}

The Actinomycetes sp. belongs to the group of endophytic microorganisms that can produce a myriad of inhibitors against pathogenic microorganisms [1]. Therefore, several studies have investigated its role as a bio-control factor including promoting plant growth, reducing the risk of the infectious pathogen, and enhancing the viability of plants under different conditions [2]. Actinomycetes took a major part in the population of root microorganisms so they easily transmit to the plant and become an endophytic body. The population includes both Streptomyces and non-Streptomyces appear in plant tissues [3]. A large number of publications in microbial compounds have reported that $45 \%$ of substances originated from Actinomycetes, $38 \%$ were from mushrooms, and $17 \%$ were from bacteria. Actinomycetes are one of the most important microorganisms due to the majority of their secondary metabolites including enzymes, antibiotics, antifungals go to industrial, agricultural, and pharmaceutical markets [4]. 
Most of these biologically active substances were discovered from terrestrial Actinomycetes which are recognized as a reliable resource for the production of antibiotics and new pharmaceutical compounds. The Actinoplane sp. and Streptomyces sp. are the most popular species that capable of producing aglucosidase inhibitors (AGIs) such as acarbose of Actinoplanes [5, 6], AGIs from Streptomyces sp. [7, 8], and other aminoglycosides, anthracyclin, glycopeptide...[9].

The ratio of discovering pharmaceutical compounds from endophytic Actinomycetes is higher than soilborne and plan Actinomycetes. A new antibiotic, Naphthomycin-K, was first discovered from endophytic Streptomyces sp. from Maytenus Hookeri-a medicinal plant that has effects against cancer. Two compounds, 5,7-dimethoxy-4-phenylcoumari and 5,7-dimethoxy-4-p-methoxylphenylcoumarin, strongly inhibited cancer growth which is frequently isolated from different plant species. Recently, they are also found in endophytic $S$. aureofaciens [10]. Methyllelaiophylin of $S$. melanosporofaciens inhibited aglucosidase with $\mathrm{IC}_{50}$ at $10 \mu \mathrm{M}$ [11]. Kaur (2016) isolated several antibiotics from endogenous Streptomyces, Micromonospora, Microbiospora, Nocardia on the leaves of the neem tree (Azadirachta indica A. Juss.) [12]. A new active substance was extracted from Streptomyces sp. OUCMDZ-3434 isolating from algae samples. These are 2 new AGIs that have been discovered. Wailupemycins $\mathrm{H}(1)$ with $\mathrm{Ki} / \mathrm{IC}_{50}$ were 16.8/19.7 $\mu \mathrm{M}$, and Wailupemycins I (2) with $\mathrm{Ki} / \mathrm{IC}_{50}$ were 6.0/8.3 M [9]. Wei (2017) isolated 24 compounds from the fermentation broth of $S$. xanthophaeus that were numbered from 1-24, and their chemical formula was elucidated by NMR. The authors have identified 3 compounds including daidzein, genistein, and gliricidin which inhibited a-glucosidase in vitro with $\mathrm{IC}_{50}$ were 174.2; 36.1 and $47.4 \mu \mathrm{M}$, respectively. The results showed the inhibitory activity was higher than that of acarbose [13].

In this study, HBC6-2 was choosed for its high production of AGIs from 6 different strains that were isolated from orange trees originated from Hoa Binh, Viet Nam. We next optimized culture conditions to increase the production and purified AGIs for further study.

\section{Materials And Methods}

\section{Microorganism}

The Streptomyces sp. strain was provided by Soil Microbiology of Laboratory, Institute of Biotechnology, Vietnam Academy of Science and Technology including HBC3-2, HBC5-1, HBC6-2, HBR5-1, HBR9-6, and HBR10-2. This Streptomyces sp. strains were isolated from the samples of root, stem, and leaf of Cao Phong orange, Hoa Binh, Vietnam.

The strain Streptomyces sp. was cultivated in ISP2 medium (g/L): 4 yeast extract, 10 malt extract, 4 dextrose, and pH 7.2. The condition for culturing Streptomyces sp. was $28^{\circ} \mathrm{C}$, shaking at $200 \mathrm{rpm}$ and $120 \mathrm{~h}$.

\section{Chemical reagent}


Acarbose, dimethyl sulfoxide (DMSO), and $p$-nitrophenyl-a-D-glucopyranoside ( $p N P G$ ) were obtained from Sigma-Aldrich. $\mathrm{K}_{2} \mathrm{HPO}_{4}, \mathrm{KH}_{2} \mathrm{PO}_{4}, \mathrm{Na}_{2} \mathrm{HPO}_{4}, \mathrm{NaH}_{2} \mathrm{PO}_{4}$ were obtained from Merck. Alpha-glucosidase, glucose, dextrose, glycerol, yeast extract, and malt extract were purchased from Biobasic INC (Canada). Sephadex ${ }^{\mathrm{TM}} \mathrm{G}-75$ was purchased from GE Healthcare Bio-Sciences AB (Sweden). All other chemicals are analytical grade, otherwise stated.

\section{Fermentation}

The Streptomyces sp. strain was streaked on the agar plate. After 7 days, colonies appeared with yellowbrown color. A single one was inoculated in a $100 \mathrm{~mL}$ propagation medium. After $72 \mathrm{~h}$, it was fermented in a medium consisting of $(\mathrm{g} / \mathrm{L}): 12$ yeast extract, 15 glucose, $\mathrm{pH} 6.5$ in $120 \mathrm{~h}$ at $28^{\circ} \mathrm{C}$ and $200 \mathrm{rpm}$ to collect the fermentation broth.

\section{Enzyme Assay}

The tests were performed in a 96-well microplate setup with slight modifications [14]. A reaction mixture of $100 \mu \mathrm{L}$ of $1-2 \mathrm{U} / \mathrm{mL}$ a-glucosidase was dissolved in $0.1 \mathrm{M}$ sodium phosphate buffer and mixed with 10 $\mu \mathrm{L}$ fermentation broth (or $\mathrm{CHCl}_{3} /$ Act extract) and $40 \mu \mathrm{L}$ of phosphate buffer solution, and then was subjected to pre-incubation in $5 \mathrm{~min}$ at $30^{\circ} \mathrm{C}$. Continuously, $100 \mu \mathrm{L}$ of 4-nitrophenyl-a-D-glucopyranoside $0.1 \mathrm{M}$ in phosphate buffer was added as substrate after pre-incubation. Next, the samples were incubated at $30^{\circ} \mathrm{C}$ for 10 min to allow a-glucosidase to react with 4-NPG and produce 4-nitrophenol. After the incubation, the formation of 4-nitrophenol in each well was measured at $405 \mathrm{~nm}$. The inhibitory activity was calculated using

$$
\% \text { Inhibition }=\frac{\Delta A c-\Delta A s}{\Delta A C} \times 100
$$

$\Delta A_{C}$ : The change in measurement of OD value before and after incubation for $5 \mathrm{~min}$ of control.

$\triangle A s$ : The change in measurement of OD value before and after incubation for $5 \mathrm{~min}$ of the sample.

DNA isolation, identification of chosen strain

The $16 \mathrm{~S}$ rDNA sequencing method was used to identify the isolated strain. Genomic DNA isolation was used to extract DNA from a potent AGIs strain [15]. The isolated DNA was amplified by PCR. The conserved gene of $16 \mathrm{~S}$ rRNA was amplified by using 9F (5'-AGAGTTTGATCCTGGCTC-3') as the forward primer and 926R (5'-CCGTCAATTCCTTTGAGTT-3') as the reverse primer. The amplified gene was sequenced on ABI PRISM 3100 Avant Genetic Analyzer. Sequence alignments were analyzed using the program MegAlign DNAStar

Culture conditions optimization 


\section{Time and temperature culture}

Unless otherwise stated, S. costaricanus EBL.HB6 was cultivated in a $250 \mathrm{~mL}$ flask with $50 \mathrm{~mL}$ ISP2 medium at $28^{\circ} \mathrm{C}$ with $200 \mathrm{rpm}$ shaking and pH of 7.2. Extracellular extract from the culturing medium was obtained and a-glucosidase inhibitory activity tests were carried out after $24,48,72,86,120,144$, 168 , and $192 \mathrm{~h}$ to select the best culture time.

To select optimum temperature for the AGIs production, S. costaricanus EBL.HB6 was cultured at different temperature from 28 to $37^{\circ} \mathrm{C}$ on ISP2 medium at $\mathrm{pH} 7.2$.

\section{Carbon source and concentration}

The effect of various additional carbon sources on the a-glucosidase inhibitors production including: starch soluble, sucrose, maltose, glucose, dextrose, and lactose at the concentration of $0.4 \%(\mathrm{w} / \mathrm{v})$ was investigated. S. costaricanus EBL.HB6 was grown in $250 \mathrm{~mL}$ shaking flasks containing $50 \mathrm{~mL}$ of the medium with $1 \%$ of malt extract, $0.4 \%$ yeast extract $(\mathrm{w} / \mathrm{v})$, and $0.4 \%(\mathrm{w} / \mathrm{v})$ of different carbon sources.

The levels of carbon source giving the highest AGIs production varied from 0.4 to $3.5 \%(\mathrm{w} / \mathrm{v})$.

\section{Nitrogen source and concentration}

The effect of various additional nitrogen sources including peptone $A$, peptone $\mathrm{B},\left(\mathrm{NH}_{4}\right)_{2} \mathrm{SO}_{4}$, yeast extract, and malt extract at the concentration of $1.0 \%(\mathrm{w} / \mathrm{v})$ was employed. In addition, the ISP2 medium was used to as a control sample.

The levels of nitrogen giving the highest AGIs production varied from 1.0 to $1.8 \%(\mathrm{w} / \mathrm{v})$.

\section{Initial medium $\mathrm{pH}$}

Fermentation in different $\mathrm{pH}$ culture media $(\mathrm{pH} 6,6.5,7,7.5$, and 8$)$ was used to determine the ideal initial $\mathrm{pH}$ in flask culture, which was changed with either $1 \mathrm{~N} \mathrm{NaOH}$ or $1 \mathrm{~N} \mathrm{HCl}$. All the tests were conducted in triplicate.

\section{Purification of the a-glucosidase inhibitors}

The $S$. costaricanus EBL.HB6 was cultured in the optimized fermentation media at $\mathrm{pH} 6.5$, incubated at $28^{\circ} \mathrm{C}$ for $120 \mathrm{~h} .100 \mathrm{~mL}$ of the cell culture broth was centrifuged at $12500 \mathrm{rpm}$ in 15

min. The fermentation broth was extracted with ethanol (80\%) for $30 \mathrm{~min}$, then centrifuged at $12500 \mathrm{rpm}$ in $15 \mathrm{~min}$. The collected liquid was lyophilized. Alpha-glucosidase inhibitory activity of the re-solubilized solution was determined, and then applied to a Sephadex ${ }^{\mathrm{TM}} \mathrm{G}-75$ column $(0.6 \times 26 \mathrm{~cm})$ pre-equilibrated with $0.02 \mathrm{M}$ phosphate buffer $(\mathrm{pH} 6.8)$ at a flow rate of $25 \mathrm{~mL} / \mathrm{hr}$ until the OD $280 \mathrm{~nm}$ was $<0.01$. The column was then eluted with $0.02 \mathrm{M}$ phosphate buffer $(\mathrm{pH} 6.8)$. The eluted fractions of $2 \mathrm{~mL}$ were collected (20 fractions). The active fraction was lyophilized and alkalized to $\mathrm{pH} 10-11$ by $0.1 \mathrm{~N} \mathrm{NaOH}$ after re-solubilized by phosphate buffer. $10 \mathrm{~mL}$ of solution was extracted with $\mathrm{n}$-butanol $(1: 1 ; \mathrm{v} / \mathrm{v})$ three 
times. The upper phase was obtained by centrifugal at $4000 \mathrm{rpm}$ in $15 \mathrm{~min}$ to collect n-butanol extract residue.

The n-butanol extract residue was re-solubilized in $30 \mathrm{ml}$ of $\mathrm{CHCl}_{3} /$ Act solvent $(1: 1 ; \mathrm{v} / \mathrm{v})$, at $40^{\circ} \mathrm{C}$, overnight, and then centrifuged at $4000 \mathrm{rpm}$ for $15 \mathrm{~min}$ to remove residue. The extract was evaporated dissolved in DMSO.

The purified AGIs were tested and detected by thin-layer chromatography (TLC) as well as infrared spectroscopy to determine the presence of the substance group. $5 \mu \mathrm{L}$ of samples were chromatographed on TLC plates (Merck, Germany) with solvent (n-butanol: acetone: $\mathrm{H}_{2} \mathrm{O} ; 5: 1: 4 ; \mathrm{v} / \mathrm{v} / \mathrm{v}$ ), then they were sprayed with iodine.

\section{Evaluation of the $\mathrm{IC}_{50}$ value}

The $\mathrm{IC}_{50}$ value was obtained by examination of the inhibition activity of a-glucosidase of purified AGIs at different levels: $5-60 \mathrm{mg} / \mathrm{mL}$. The line graph equation was established as a function of the purified AGIs concentration $(x)$ and inhibitory activity $(y)[16]$. The $\mathrm{IC}_{50}$ value is the level of purified AGls value that inhibit 50\% a-glucosidase activity.

\section{Statistical analysis}

All measurements were carried out in triplicate. The means were presented for the averages of experiments.

\section{Results}

\section{Screening of a-glucosidase inhibitory activity for Streptomyces sp. strains}

The fermentation broth of 6 strains of Streptomyces sp. was examined with a-glucosidase activity. Streptomyces sp. HBC6-2 displayed the highest a-glucosidase inhibitory activity by $68.98 \%$ among Streptomyces sp. strains (Fig. 1a). The strain Streptomyces sp. HBC6-2 produced melanin yellow pigments, non-fragmenting substrate mycelia (hypha diameter around $10 \mathrm{~mm}$ ), and formed spiral spores containing 10-50 spores. The color of the aerial and substrate mycelia of Streptomyces sp. HBC6-2 was gray-brown and yellow-brown (Fig. 1b).

16S rRNA sequencing of Streptomyces sp. HBC6-2 was identified. BLAST results of 16S rRNA from HBC62 strain indicated that this 16 S rRNA segment showed $99.69 \%$ identity with 16 S rRNA from $S$. costaricanus MR7 (KY753206), 99.59\% to S. costaricanus MJM5482 (FJ799179) (Fig. 1c). It was registered on GenBank with the code MT 453944.1.

\section{Culture conditions optimization}


To determine the optimal conditions for producing AGIs from S. costaricanus EBL.HB6, the culture parameters such as culture time, temperature, carbon, and nitrogen of source at different levels and initial $\mathrm{pH}$ were investigated.

\section{Effect of culture time and temperature}

The incubation time for AGIs production by $S$. costaricanus EBL.HB6 was carried out in the ISP2 medium at $28^{\circ} \mathrm{C}$ with shaking $200 \mathrm{rpm}$, and an initial pH of 7.2. After $120 \mathrm{~h}$ of culture, the a-glucosidase inhibitory activity of extracellular extracts of $S$. costaricanus EBL.HB6 reached maximal values of $70.15 \%$. Then, it slightly decreased and after $192 \mathrm{~h}$ of culture as low as $42.63 \%$ (Fig. 2a).

The temperature did not significantly affect the AGIs activity of the $S$. costaricanus EBL.HB6. This strain had stable activity in the temperature range $28-37^{\circ} \mathrm{C}$, however, it is capable of producing highly active aglucosidase inhibitors at $28^{\circ} \mathrm{C}$ (Fig. 2b).

\section{Effect of carbon source at different levels}

Glucose-containing medium showed the highest a-glucosidase inhibitory activity of $72.42 \%$, followed by other medium supplemented with sucrose (44.68\%); malt extract (32.05\%). However, starch soluble and maltose-containing medium showed the lowest inhibition activity (Fig. 2c).

Dextrose was replaced by glucose dramatically increased the AGIs production by S. costaricanus EBL.HB6 from $68.3 \%$ in the media containing $0.4 \%(\mathrm{w} / \mathrm{v})$ of glucose to the maximum $76.25 \%$ at glucose $(1.5 \%)$, and then gradually decreased to $57.5 \%$ in the medium containing $3.5 \%$ of glucose (Fig. 2d).

\section{Effect of nitrogen source at its concentration}

Culture medium supplementing different with nitrogen source exhibited different a-glucosidase inhibitory activity (Fig. 3a). Yeast extract adding media enhance the inhibition activity of the crude extract by $77.07 \%$. In contrast, Peptone B and malt extract supplementing media exhibited a lower inhibition activity of $51.44 \%$ and $52.72 \%$, respectively, and the lowest one is $\left(\mathrm{NH}_{4}\right)_{2} \mathrm{SO}_{4}$ containing media.

Especially, the fermented media only containing of yeast extract (1.2\%) increased aglucosidase inhibitory to $87.1 \%$ while ISP2 media was reached $68.98 \%$ (Fig. 3b).

\section{Effect of initial pH}

Five different initial pH $6,6.5,7,7.5$, and 8 were examined for their effect on AGIs production by $S$. costaricanus EBL.HB6. The optimal initial culture $\mathrm{pH}$ for AGls production by $S$. costaricanus EBL.HB6 was 6.5 (Fig 3c). At this $\mathrm{pH}$, the a-glucosidase inhibitory activity of extracellular extracts of $S$. costaricanus EBL.HB6 reached maximal inhibitory activity of $83.58 \%$. An initial culture $\mathrm{pH}$ lower or higher than 6.5 reduced AGIs production by $S$. costaricanus EBL.HB6. These findings 
suggested that the $\mathrm{pH}$ medium has a considerable impact on AGIs production

by $S$. costaricanus EBL.HB6.

\section{Determination of a-glucosidase inhibitory activity under optimal conditions}

The S. costaricanus EBL.HB6 strain was grown in the optimal medium containing 1.5\% of glucose, $1.2 \%$ of yeast extract, at $28^{\circ} \mathrm{C}$ with initial pH of 6.5 for $120 \mathrm{~h}$. The result showed the a-glucosidase inhibitory activity of extracellular extracts of $S$. costaricanus EBL.HB6 was $84.97 \%$ (Fig. $3 \mathrm{~d}$ ). These results were 1.2 times higher than those obtained before optimization (69.77\%).

\section{Purification of a-glucosidase inhibitors}

The ethanol extract of $S$. costaricanus EBL.HB6 was purified by passage over a Sephadex ${ }^{\mathrm{TM}} \mathrm{G}$ 75 column. These fractions were tested for a-glucosidase inhibitory activity and all were positive (Fig. 4a). Fraction 9-13 showed the highest a-glucosidase inhibitory activity of $84 \%$ (fraction 10 ) and $50 \%$ to $70.53 \%$, respectively. Fractions 10 were then extracted by n-butanol three times and n-butanol extract residue was re-solubilized in $\mathrm{CHCl}_{3} /$ Act solvent to obtain purified inhibitors.

The purity of the purified inhibitors was assessed by TLC methods. A spot with $\mathrm{Rf}=0.71$ was observed (Fig. 4b- land 4) and the yield of the purification process was $5 \%$ and exhibited inhibition of a-glucosidase activity was $45.47 \%$ (Table 1 ).

We next investigated the a-glucosidase inhibitor activity of purified AGIs by measuring the $\mathrm{IC}_{50}$ value. The purified AGls were dissolved in DMSO at different levels. The $\mathrm{IC}_{50}$ of purified AGIs was $9.59 \mathrm{mg} / \mathrm{mL}$ (Fig. 4c).

The FT-IR spectrum showed that major functional groups appeared such as Ar-H vibration in aromatic ring, imide region, $\mathrm{C}=\mathrm{C}$ oscillation in the aromatic ring, and oscillation outside $\mathrm{mp} \mathrm{Ar-H} \mathrm{(Fig.} 4 \mathrm{~d}$ ).

\section{Discussion}

Several studies reported that actinobacteria were more prevalent in the discovery of a-glucosidase inhibitors. Abdulkhair (2018) isolated 55 strains of marine Actinomycetes, of which, only 7 strains were found to have a-glucosidase inhibitory activity [17]. S Ganesan, S Raja, P Sampathkumar, K Sivakumar and $T$ Thangaradjou [18] identified 41 bacteria strains that exhibited glucosidase inhibitory activity from 181 isolated strains of marine actinobacteria [18]. The study by Cansigno and his colleagues discovered that Veracruz seaweed was capable of synthesizing a-amylase and AGIs [19].

The culture duration of $S$. costaricanus EBL.HB6 produced the AGIs shorter than Streptomyces sp. strain OUCMDZ-3434 (8 days) [9], possibly because of $S$. costaricanus EBL.HB6 produced the secondary metabolite during the growth and development of Actinomycetes. In which, Streptomyces sp. OUCMDZ3434 produced a phenolic compound that takes a long time to produce. During nutrient depletion, metabolites are generally generated during the late growth stage of bacteria [20]. This finding was in 
agreement with the earlier study in which in the presence of glucose, the synthesis of acarbose, AGIs used to treat diabetes type 2 , was produced $[6,21]$.

The AGIs was purified from the culture supernatant showed a-glucosidase inhibitory activity of $45.47 \%$ and a spot with a coefficient of Rf $=0.71$ on TLC (Fig. 4b, lane 4). The purified inhibitor showed the final yield of the purification procedure was $5 \%$ (Table 1 ).

These results of the FT-IR spectrum suggested that AGIs production S. costaricanus EBL.HB6 could be an alkaloid but not a protein from Streptomyces sp. AD7 [17], or phenolic compounds from Streptomyces sp. OUCMDZ-3434 [9], S. xanthophaeus [13], or dibutyl phthalate from the strain S. melanosporofaciens [22]. This result is further evidence of the diversity in AGIs production by different Streptomyces sp. strains. Purified AGIs from different Streptomyces sp. strains may be obtained the different AGIs.

In our recent study, we determined the $\mathrm{IC}_{50}$ of the n-butanol extract was $13.89 \mu \mathrm{g} / \mathrm{mL}$ from Oceanimonas smirnovii EBL6, while acarbose (Sigma) was $31.16 \mu \mathrm{g} / \mathrm{mL}$ [23]. In this study, IC ${ }_{50}$ value of purified AGIs was $9.59 \mu \mathrm{g} / \mathrm{mL}$. This may be suggested that $S$. costaricanus EBL.HB6 had potential for the treatment of type II diabetes for further study. Previously, ethyl acetate extracted containing AGIs from Streptomyces sp. IPBCC. b. 15. 1539 with $\mathrm{IC}_{50}$ value was $0.047 \mu \mathrm{g} / \mathrm{mL}$ [16]; $21.17 \mu \mathrm{g} / \mathrm{mL}$ from Streptomyces sp. S2A [7]; $3.1 \mathrm{mg} / \mathrm{mL}$ A. oryzae N159-1 [24]; $5.625 \mu \mathrm{g} / \mathrm{mL}$ from A. awamori [25]; $1.25 \mu \mathrm{g} / \mathrm{mL}$ from Streptomyces strain PW638 [8]; $0.062 \mathrm{mg} / \mathrm{mL}$ from Streptomyces sp. TVS1 [26]; $500 \mu \mathrm{g} / \mathrm{mL}$ from Arthrobacter enclensis [27]. Daidzein, genistein, and gliricidin from $S$. xanthophaeus with $\mathrm{IC}_{50}$ values of $174.2,36.1$ and $47.4 \mu \mathrm{M}$, respectively [13]; two new AGIs from Streptomyces sp. OUCMDZ-3434 with IC $\mathrm{IC}_{50}$ values of 19.7 and 8.3 $\mu \mathrm{M}$, respectively [9]. So, $\mathrm{IC}_{50}$ value may be related to the purity level of the extracts or compound.

In conclusion, the isolating HBC6-2 was chosen for its high production of AGls from 6 different Streptomyces sp. strains isolated from the samples of root, stem, and leaf of Cao Phong orange and its was registered on GenBank with the code MT 453944.1.

The optimal culture medium for fermentation of AGIs from S. costaricanus EBL.HB6 composed of $(\mathrm{g} / \mathrm{L})$ : glucose 15, yeast extract 12; $\mathrm{pH}$ 6.5. The optimal incubated conditions for the production were $120 \mathrm{~h}$, $28^{\circ} \mathrm{C}$, and shaking speed of $200 \mathrm{rpm}$. Combination of all the optimal conditions, the a-glucosidase inhibition activity exhibited the highest point at $84.97 \%$, increased by a factor of 1.2 times in comparison with the initial condition. In addition, we successfully purified and evaluated of $\mathrm{IC}_{50}$ value of AGIs from $S$. costaricanus EBL.HB6. The significant inhibitory a-glucosidase activity of $S$. costaricanus suggests its potential utility as an alternative to make biosimilars products for the treatment of type II diabetes.

\section{Declarations}

Acknowledgement

This work was financially supported by the Vietnam Academy of Science and Technology: "Isolation, selection, and purification of secondary metabolites inhibiting a-glucosidase, oriented for the treatment of 
type 2 diabetes from microorganism isolated in Vietnam". Code number KHCBSS.01/19-21. Vietnam Academy of Science and Technology. 2019-2021.

\section{Funding}

This study was funded by the Vietnam Academy of Science and Technology with the grant number of KHCBSS.01/19-21 (2019-2021).

\section{Conflict of interest}

The authors declare no competing interests.

\section{Availability of data and material}

The sequence of bacteria strain was deposited in GenBank with accession no. MT 453944.1. All data generated or analysed during this study are included in this published article.

\section{Ethics declarations}

\section{Ethical statement}

This article does not contain any studies with human participants or animals performed by any of the authors.

\section{Consent for publication}

All authors have approved the submitted version and give consent for publication.

\section{Author's Contribution}

DTT and NTT designed the experimental setup, assisted with data analysis and manuscript preparation. MVH performed experiments of screening of $S$. costaricanus EBL.HB6. NPDN and DTMA performed optimization of a-glucosidase inhibitory activity. NTT and PTHT purified and determined on the $\mathrm{IC}_{50}$ value of the AGIs. DTT initiated the project, read and approved the final manuscript. All authors read and approved the final manuscript.

\section{References}

1. Lee SO, Choi GJ, Choi YH, Choi YH, Jang KS, Park DJ, Kim CJ, Kim JC (2008) Isolation and characterization of endophytic actinomycetes from Chinese cabbage roots as antagonists to Plasmodiophora brassicae. J Microbiol Biotechnol 18(11):1741-1746

2. Strobel G, Daisy B, Castillo U, Harper J (2004) Natural products from endophytic microorganisms. J Nat Prod 67(2):257-268 
3. Shutsrirung A, Chromkaew Y, Pathom-Aree W, Choonluchanon S, Boonkerd N (2013) Diversity of endophytic actinomycetes in mandarin grown in northern Thailand, their phytohormone production potential and plant growth promoting activity. J Soil Sci Plant Nutr 59:322-330

4. Sharma M, Dangi P, Choudhary M (2014) Actinomycetes: Source, identification, and their applications. Int J Curr Microbiol App Sci 3(2):801-832

5. Wang YJ, Liu LL, Feng ZH, Liu ZQ, Zheng YG (2011) Optimization of media composition and culture conditions for acarbose production by Actinoplanes utahensis ZJB-08196. Microb Biotechnol 27:2759-2766

6. Sun LH, Li MG, Wang YS, Zheng YG (2012) Significantly enhanced production of acarbose in fedbatch fermentation with the addition of S-adenosylmethionine. Microb. Biotechnol 22:826-831

7. Siddharth S, Vittal RR (2018) Evaluation of antimicrobial, enzyme inhibitory, antioxidant and cytotoxic activities of partially purified volatile metabolites of marine Streptomyces sp.S2A. Microorganisms 6:72

8. Meng P, Zhou XX (2012) a-Glucosidase inhibitory effect of a bioactivity guided fraction GIB-638 from Streptomyces fradiae PWH638. Med Chem Res 21(12)

9. Chen Z, Hao J, Wang L, Wang Y, Kong F, Zhub W (2016) New a-glucosidase inhibitors from marine algae-derived Streptomyces sp. OUCMDZ-3434. Sci Rep. doi:10.1038/srep20004

10. Qin S, Xing K, Jiang JH, Xu LH, Li WJ (2010) Biodiversity, bioactive natural products and biotechnological potential of plant-associated endophytic actinobacteria. Appl Microbiol Biotechnol 89(3):457-473

11. Lee D, Woo JK, Kim D, Kim M, Cho SK, Kim JH, Park SP, Lee HY, Riu KZ, Lee DS (2011) Antiviral activity of methylelaiophylin, an alpha-glucosidase inhibitor. J Microbiol Biotechnol 21(3):263-266

12. Kaur N (2016) Endophytic actinomycetes from Azadirachta indica A. Juss.: Characterization and anti-microbial activity. Int J Adv Res 4(6):676-684

13. Wei J, Zhang XY, Deng S, Cao L, Xue QH, Gao JM (2017) a-Glucosidase inhibitors and phytotoxins from Streptomyces xanthophaeus. Nat Prod Res 31(17):2062-2066

14. Koh WY, Uthumporn U, Rosma A, Irfan AR, Park YH (2018) Optimization of a fermented pumpkinbased beverage to improve Lactobacillus mali survival and a-glucosidase inhibitory activity: A response surface methodology approach. Food Sci Hum Wellness 7:57-70

15. Quyen DT, Dao TT, Nguyen SLT (2007) A novel esterase from Ralstonia sp. M1: gene cloning, sequencing, high-level expression and characterization. Protein Expr Purif 51(2):133-140

16. Lestari Y, Rahminiwati M, Velina Y (2015) Metabolites activity of endophytic Streptomyces sp. IPBCC. b.15.1539 from Tinospora crispa I. miers: a-glucosidase inhibitor and anti-hyperglycemic in mice. Int J Pharm Pharm Sci 7(6):235-239

17. Abdulkhair WM, Abdel-All WS, Bahy RH (2018) Genetic improvement of antidiabetic alphaglucosidase inhibitor producing Streptomyces sp. Int J Pharm Pharm Sci 10(5):77-84 
18. Ganesan S, Raja S, Sampathkumar P, Sivakumar K, Thangaradjou T (2011) Isolation and screening of a -glucosidase enzyme inhibitor producing marine actinobacteria. Afr J Microbiol Res 5(21):34373245

19. Landa-Cansigno C, Hernández-Domínguez EE, Monribot-Villanueva JL, Licea-Navarro AF, Mateo-Cid LE, Segura-Cabrera A, Guerrero-Analco JA (2020) Screening of Mexican tropical seaweeds as sources of a-amylase and a-glucosidase inhibitors. Algal Res.

doi:https://doi.org/10.1016/j.algal.2020.101954

20. Bibb MJ (2005) Regulation of secondary metabolism in Streptomycetes. Curr Opin Microbiol $8(2): 208-215$

21. Wei SJ, Cheng X, Huang L, Li KT (2010) Medium optimization for acarbose production by Actinoplanes sp. A56 using the response surface methodology. Afr. J Biotechnol 9:1849-1854

22. Lee DS (2000) Dibutyl phthalate, an a-glucosidase inhibitor from Streptomyces melanosporofaciens. J Biosci Bioeng 89(3):271-273

23. Nguyen THT, Tang DYY, Chew KW, Nguyen TL, Le TH, Nguyen TC, Hoang TY, Nguyen TT, Nguyen TT, Show PL, Do TT (2021) Discovery of a glucosidase inhibitors from marine microorganisms: Optimization of culture conditions and medium composition. Mol Biotechnol. doi:https://doi.org/10.1007/s12033-021-00362-3

24. Kang MG, Yi SH, Lee JS (2013) Production and characterization of a new a-glucosidase inhibitory peptide from Aspergillus oryzae N159-1. Mycobiology 41(3):149-154

25. Singh B, Kaur A (2015) Antidiabetic potential of a peptide isolated from an endophytic Aspergillus awamori. J Appl Microbiol 120:301-311

26. Nguyen NT, Nguyen CTG, Luong AH, Nguyen MC (2019) Studying on appropriate conditions for the production of a-amylase and a-glucosidase inhibitors from Streptomyces sp. TVS1. CTUJS 55(2):49-56

27. Mawlankar RB, Dharne MS, Dastager SG (2020) Isolation of potent alpha-glucosidase inhibitor from a novel marine bacterium Arthrobacter enclensis. SN Applied Sciences 2:474

\section{Tables}

Table 1. Purification efficacy of a-glucosidase inhibitiors

\begin{tabular}{|llll|}
\hline Purification steps & Amounts & Yield & a-glucosidase inhibition (\%) \\
& $(\mathrm{g})$ & $(\%)$ & \\
\hline The fermentation broth & 1.814 & & 84.97 \\
\hline Sephadex ${ }^{\mathrm{TM}}$ G-75 (fraction 10) & 0.4261 & 23.49 & 84.0 \\
\hline n-butanol extract & 0.1492 & 8.2 & 54.37 \\
\hline The purified AGls & 0.0907 & 5.0 & 45.47 \\
\hline
\end{tabular}


Figures
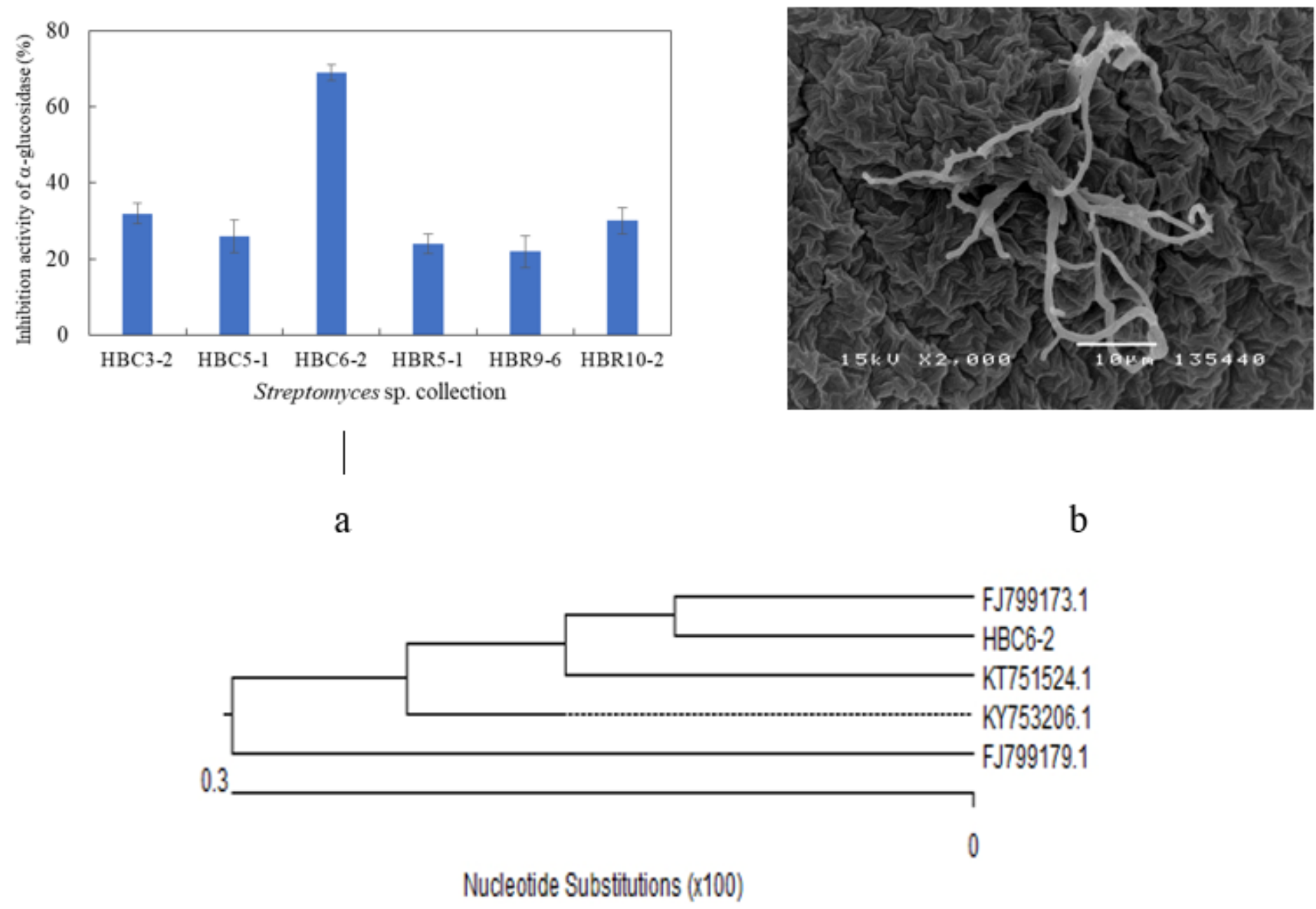

$\mathrm{C}$

\section{Figure 1}

Screening of a-glucosidase inhibitory activity from the fermentation broth of 6 Streptomyces sp. strains (a); Substrate mycelia (magnification a 2000) (b); Taxonomy of Streptomyces sp. HBC6-2 (c) 


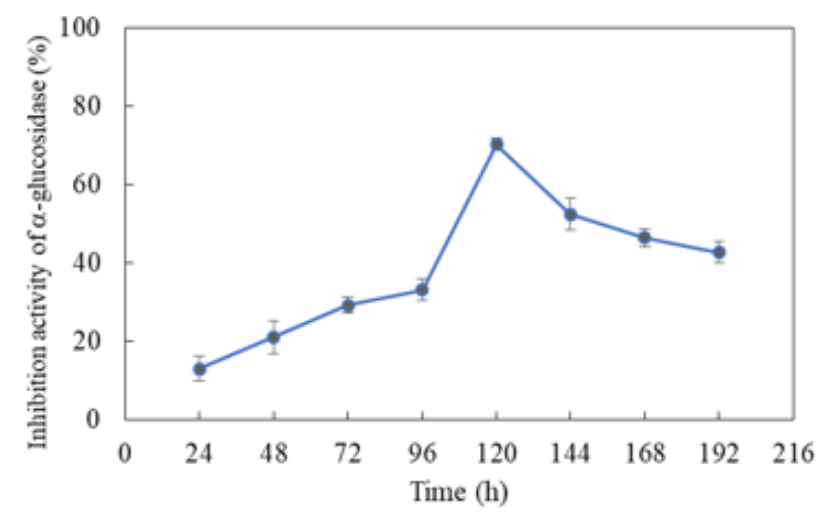

a

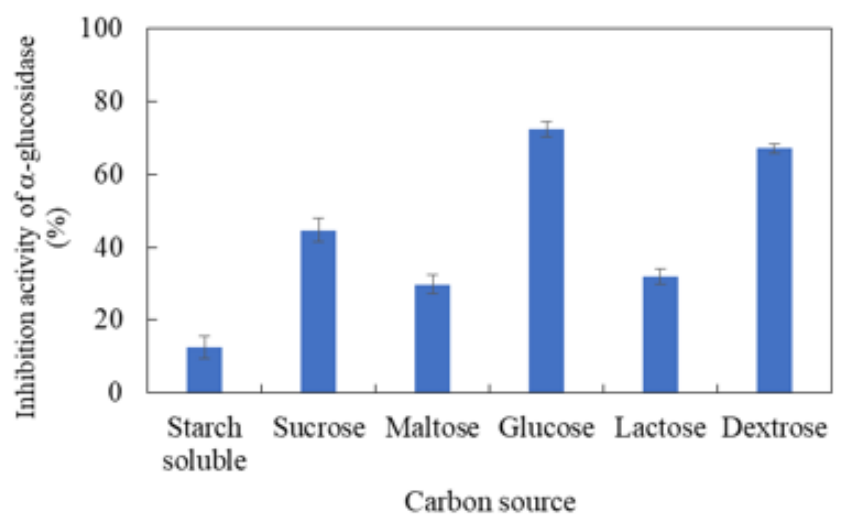

c

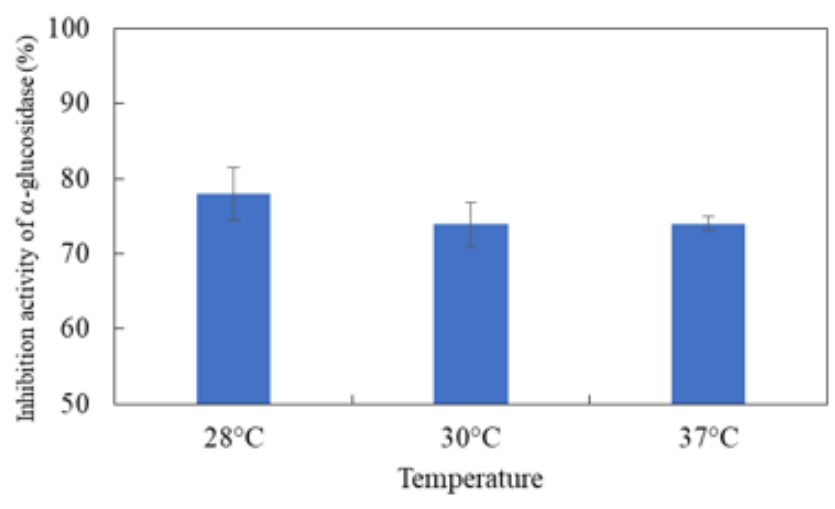

b

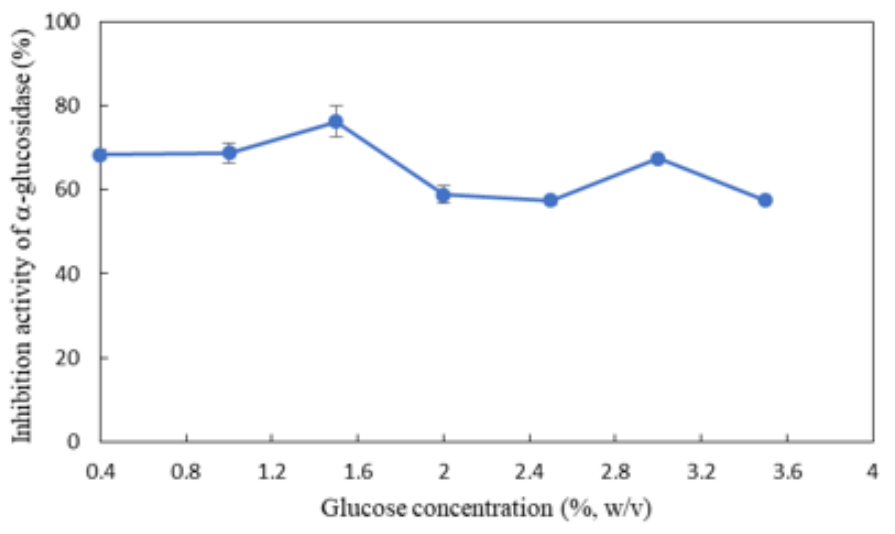

d

Figure 2

Effect of incubation time (a), temperature (b), carbon source (c) and glucose concentration (d) on the production of AGIs from S. costaricanus EBL.HB6 


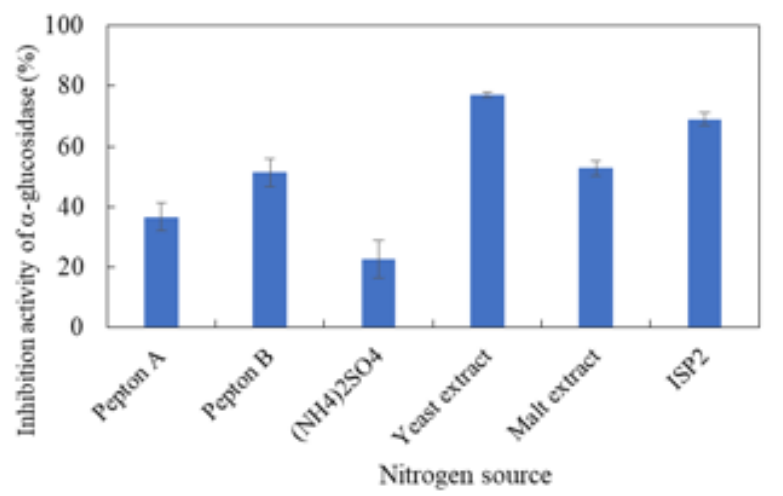

a

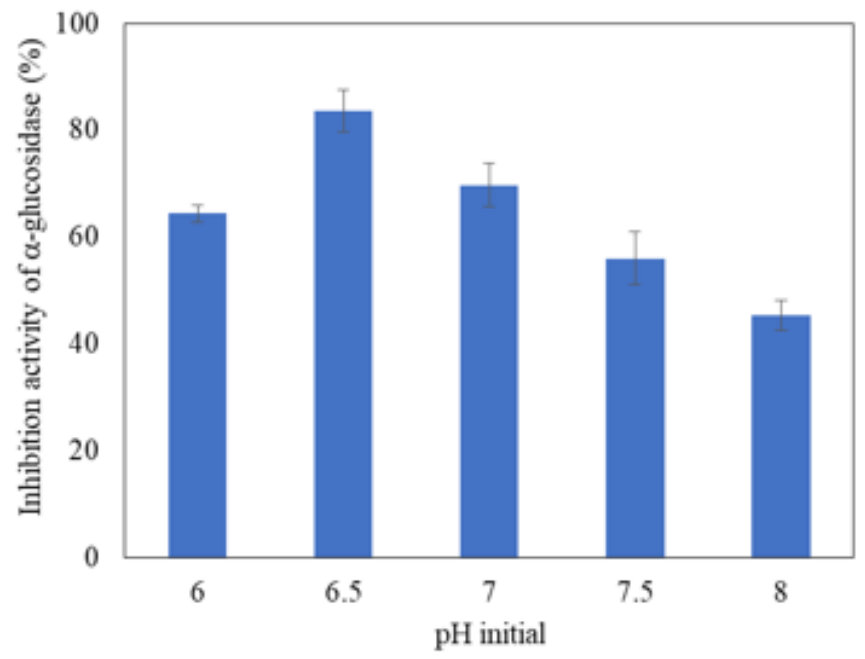

c

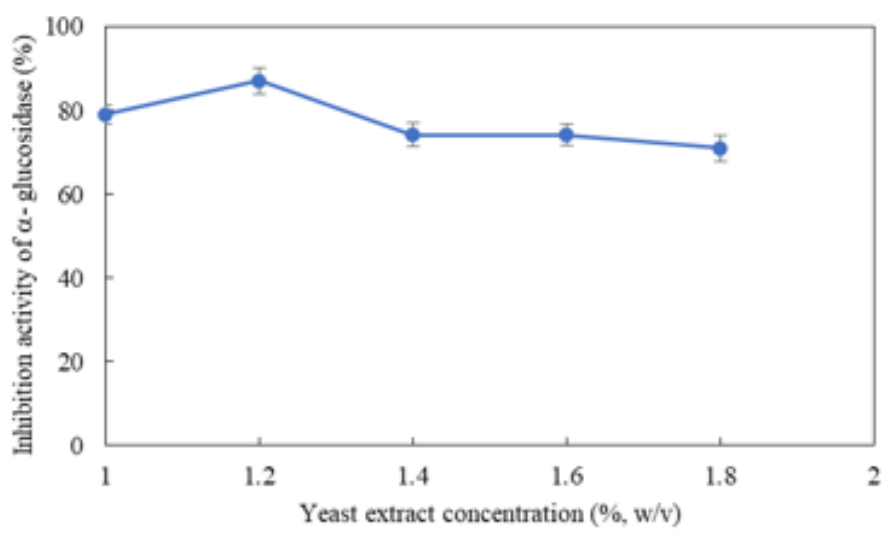

b

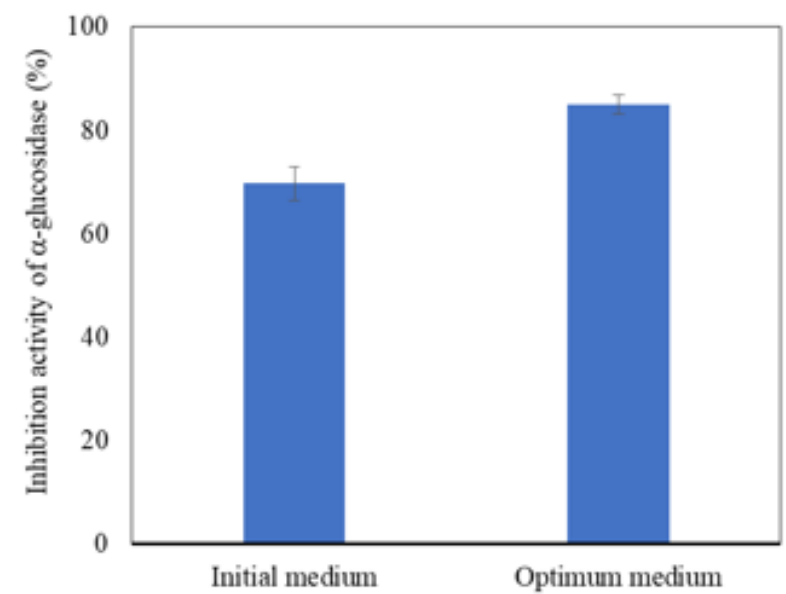

d

Figure 3

Effect of nitrogen source (a), yeast extract concentration (b), pH medium (c) on the production of AGIs from S. costaricanus EBL.HB6 and inhibitory activity of a-glucosidase in ISP2 medium and optimal medium (d) 


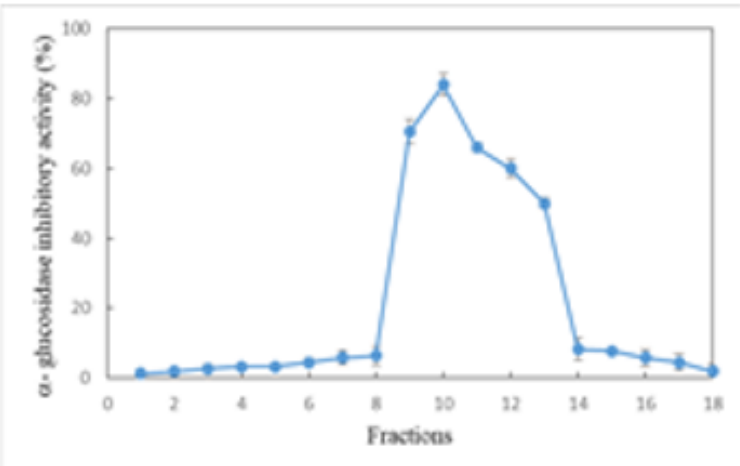

a$$
\text { (1) }
$$

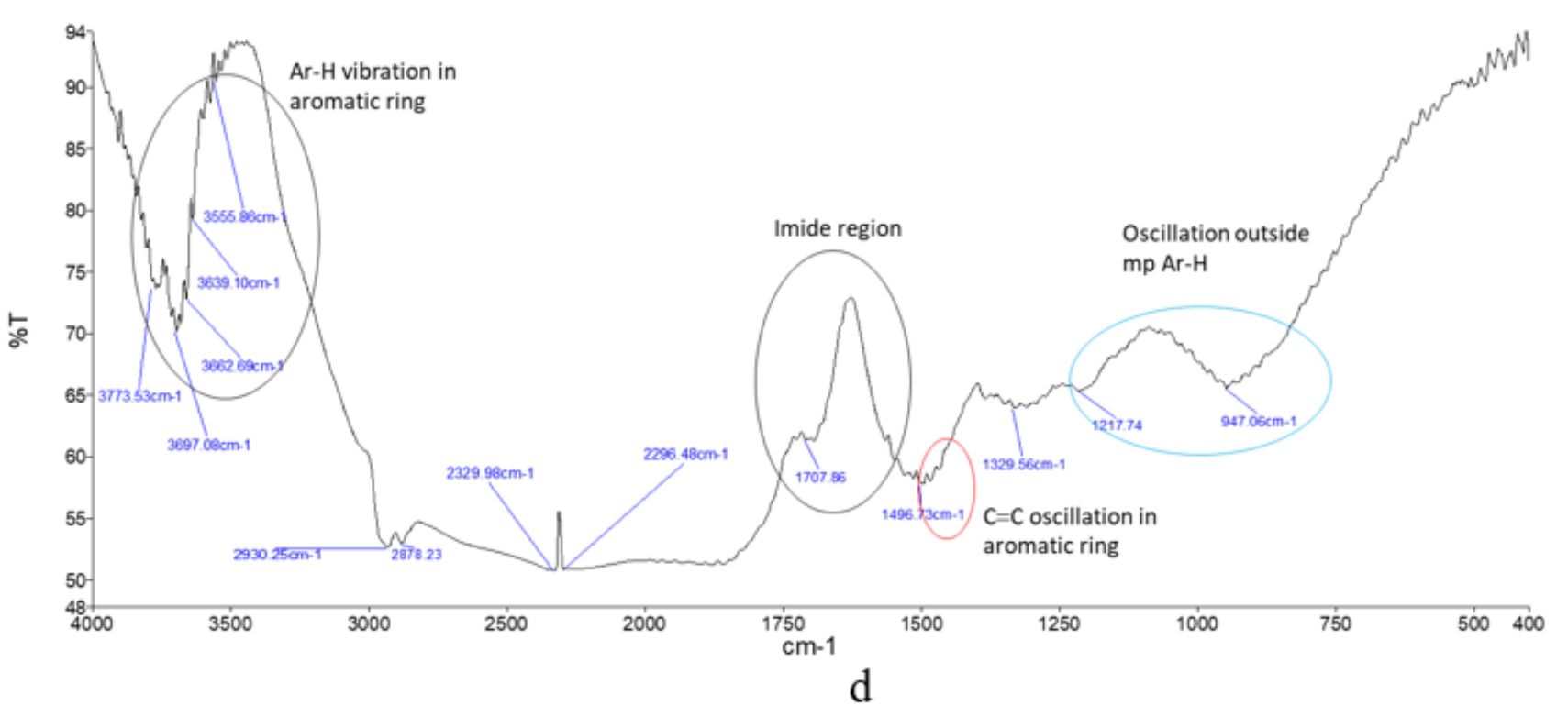

\section{Figure 4}

Fractional inhibitory activity of the samples was purified by SephadexTM G-75 column (a); The appearance of purified compound on TLC chromatography (b) (land 1: fraction 10; land 2: The fermentation broth; land 3: n-butanol extract; land 4: the purified AGIs after extracted by $\mathrm{CHCl} 3 / \mathrm{Act}$ extract); IC50 value (c) and FT-IR spectrum of purified AGIs from S. costaricanus EBL.HB6

\section{Supplementary Files}

This is a list of supplementary files associated with this preprint. Click to download.

- Graphicalabstract.pdf 